\title{
Cold-induced mortality of invasive Burmese pythons in south Florida
}

\author{
Frank J. Mazzotti • Michael S. Cherkiss • \\ Kristen M. Hart • Ray W. Snow $\cdot$ Michael R. Rochford • \\ Michael E. Dorcas $\cdot$ Robert N. Reed
}

Received: 17 March 2010/Accepted: 1 June 2010/Published online: 15 June 2010

(C) The Author(s) 2010. This article is published with open access at Springerlink.com

\begin{abstract}
A recent record cold spell in southern Florida (2-11 January 2010) provided an opportunity to evaluate responses of an established population of Burmese pythons (Python molurus bivittatus) to a prolonged period of unusually cold weather. We observed behavior, characterized thermal biology, determined fate of radio-telemetered $(n=10)$ and non-telemetered $(n=104)$ Burmese pythons, and analyzed habitat and environmental conditions experienced by pythons during and after a historic cold spell. Telemetered pythons had been implanted with radio-transmitters and temperature-recording data loggers prior to the cold snap. Only one of 10
\end{abstract}

F. J. Mazzotti $(\bowtie) \cdot$ M. S. Cherkiss · M. R. Rochford Ft. Lauderdale Research and Education Center, University of Florida, 3205 College Ave., Davie, FL 33314, USA e-mail: fjma@ufl.edu

K. M. Hart

US Geological Survey, Southeast Ecological Science

Center, 3205 College Ave., Davie, FL 33314, USA

R. W. Snow

National Park Service, Everglades National Park, 40001 State Road 9336, Homestead, FL 33034, USA

M. E. Dorcas

Department of Biology, Davidson College, P.O. Box 7118, Davidson, NC 28035, USA

R. N. Reed

US Geological Survey, Fort Collins Science Center, 2150 Centre Ave., Fort Collins, CO 80526, USA telemetered pythons survived the cold snap, whereas 59 of $99(60 \%)$ non-telemetered pythons for which we determined fate survived. Body temperatures of eight dead telemetered pythons fluctuated regularly prior to 9 January 2010, then declined substantially during the cold period (9-11 January) and exhibited no further evidence of active thermoregulation indicating they were likely dead. Unusually cold temperatures in January 2010 were clearly associated with mortality of Burmese pythons in the Everglades. Some radiotelemetered pythons appeared to exhibit maladaptive behavior during the cold spell, including attempting to bask instead of retreating to sheltered refugia. We discuss implications of our findings for persistence and spread of introduced Burmese pythons in the United States and for maximizing their rate of removal.

Keywords Python molurus - Florida Everglades · Cold temperatures - Invasive species ·

Mortality $\cdot$ Thermoregulation

\section{Introduction}

Invasive alien reptiles present an increasing challenge to conservation of biological diversity (Wilcove et al. 1998; Kraus 2009). The United States dominates the world trade in live reptiles (Hoover 1998; Franke and Telecky 2001), and the state of Florida alone currently hosts more established alien reptiles than any other state or nation (Meshaka et al. 2004; Kraus 
2009). Many of the more than 40 exotic reptile species established in Florida are confined to urban or otherwise manmade habitats such as backyards and canals; however, several species (e.g., Burmese python, Python molurus bivittatus) have successfully invaded natural habitats. The Burmese python is native to Southeast Asia and is established in natural areas in southern Florida such as Everglades National Park (ENP) (Snow et al. 2007a).

Burmese pythons are habitat and dietary generalists (Reed and Rodda 2009). Considerable concern has been expressed over their impacts on south Florida ecosystems, particularly in ENP, where Burmese pythons consume primarily birds and mammals (Snow et al. 2007b). Ecological and economic impacts of invasive animals such as pythons depend on types and magnitude of impacts (e.g., predation on or competition with native species) and geographic extent of invasion (Pimentel et al. 2005; Kraus 2009).

Although climate is often proposed as a primary factor limiting potential geographic extent of invading species, predicting potential range of an invasive species is difficult because of a poor understanding of predictors of invasive ranges (Hayes and Barry 2008), observations that native range climate may underpredict invasive range distribution (Fitzpatrick et al. 2007; Duncan et al. 2009), and methodological or statistical uncertainties (Randin et al. 2006; Beaumont et al. 2009; Phillips et al. 2009; Reed and Rodda 2009). As an example of the latter, several attempts have been made to use native-range climatic variables to predict potential distribution of Burmese pythons in the United States, but results have been inconsistent and even contradictory (Pyron et al. 2008; Rodda et al. 2009; van Wilgen et al. 2009).

The native range of Burmese pythons extends from tropical zones in Southeast Asia (including Vietnam, Cambodia, Laos, and Thailand) to warm temperate zones in China and Nepal (Groombridge and Luxmoore 1991; Zhao and Adler 1993; Whitaker and Captain 2004). Winter temperatures may exert some influence over northern range limits of Burmese pythons. However, little is known about thermal physiology and thermoregulatory behavior of pythons in native habitats (Alexander 2007; Reed and Rodda 2009). A recent record cold spell in southern Florida (NOAA 2010) provided an opportunity to evaluate responses of an existing Florida population of
Burmese pythons to a prolonged period of unusually cold weather.

During 2-11 January 2010, south Florida experienced record cold temperatures (NOAA 2010). During 9-11 January, air temperatures remained at or below $10^{\circ} \mathrm{C}$ for at least $48 \mathrm{~h}$. A low of $1.6^{\circ} \mathrm{C}$ on the morning of 10 January tied an all-time record low for Miami. Record low maximum air temperatures $\left(9^{\circ} \mathrm{C}\right)$ were recorded in Miami and Naples on 10 January 2010 (NOAA 2010). On the morning of 11 January, monitoring stations across south Florida recorded air temperatures ranging from -4 to $0^{\circ} \mathrm{C}$. West Palm Beach and Miami both set record lows $\left(0.5\right.$ and $2.2^{\circ} \mathrm{C}$, respectively) for 11 January. Between 2 and 11 January, West Palm Beach and Naples set records for number of days (10) with air temperature lows at or below $7.2^{\circ} \mathrm{C}$ (NOAA 2010). A combination of duration and extremes of this historic cold period resulted in extensive press coverage of mortality of native and alien wildlife including manatees, sea turtles, crocodiles, numerous species of fish, iguanas, and pythons (Fantz 2010; Quinlan 2010; Waters 2010).

Our objectives were to report on behavior, thermal biology, and fate of telemetered pythons $(n=10)$, fate of non-telemetered pythons $(n=104)$, and habitat and environmental conditions experienced by pythons during and immediately after the historic cold spell in southern Florida.

\section{Methods}

Adult Burmese pythons used for telemetry $(n=10)$ were obtained from ENP. For each python we measured snout-vent length (SVL), total length (TL), tail girth, and mass at the time of transmitter implantation. Each python was implanted intraperitoneally (Reinert and Cundall 1982; Hardy and Greene 1999, 2000) with two VHF radio transmitters obtained from Holohil Systems Ltd. Small transmitters (11 g, $40 \times 11 \mathrm{~mm}$ ) were used for snakes less than $16 \mathrm{~kg}$ and larger transmitters $(25 \mathrm{~g}, 45 \times 11 \mathrm{~mm})$ were used in larger snakes. Transmitter weights were less than $0.5 \%$ of each snake's body mass. We also inserted one temperature-recording data logger into each snake. Pythons less than $16 \mathrm{~kg}$ received a smaller ( $3 \mathrm{~g}$, $16 \times 6 \mathrm{~mm}$ ) data logger (Maxim Integrated Products) and larger snakes received a larger $(30 \mathrm{~g}, 30 \times 40 \times$ $10 \mathrm{~mm}$ ) data logger (Onset Computer Corporation). 
Each data logger was programmed to record body temperature $(\mathrm{Tb})$ every $30 \mathrm{~min}$ for one year. Simultaneously, we deployed a temperature data logger in each of two biophysical snake models constructed of $105 \times 5 \mathrm{~cm}$ copper pipe painted black. Biophysical snake models have similar thermal properties to live snakes and allow detailed interpretation of thermal data (see Peterson et al. 1993 for explanation). Most pythons were acclimated to the wild well before the onset of these record cold temperatures and had the transmitters surgically implanted 2 weeks to 9 months before this cold event. The two most recent surgeries were conducted 2 weeks and four and a half weeks prior to the cold event.

As part of an ongoing python radio-tracking project, we located each telemetered snake weekly using fixed-wing aircraft flying at an altitude of $150 \mathrm{~m}$ and a speed of $175 \mathrm{kph}$. During the cold spell, we supplemented our weekly fixed-wing flights with helicopter flights and/or on the ground tracking of each snake 1-2 times per week until confirmation of death or survival. We 'walked in' on all snakes that had been located from the air for visual identification and to obtain a GPS location. We accessed snakes on the ground either via helicopter or by foot from the nearest vehicle access point. When we sighted a snake we recorded details on surrounding habitat (e.g., tree island, marsh, hammock, road, levee), position, and health. We took in situ pictures of each python and recovered carcasses of dead snakes for necropsy and to remove temperature data loggers. Python Tb's were compared to model temperatures using linear regression.

To search for other Burmese pythons throughout the Everglades landscape, we surveyed hammocks, ponds, tree islands, canals, levees, roads, and trails by air, vehicle, boat, and foot between 2 January 2010 and 4 February 2010 (Fig. 1); we also solicited

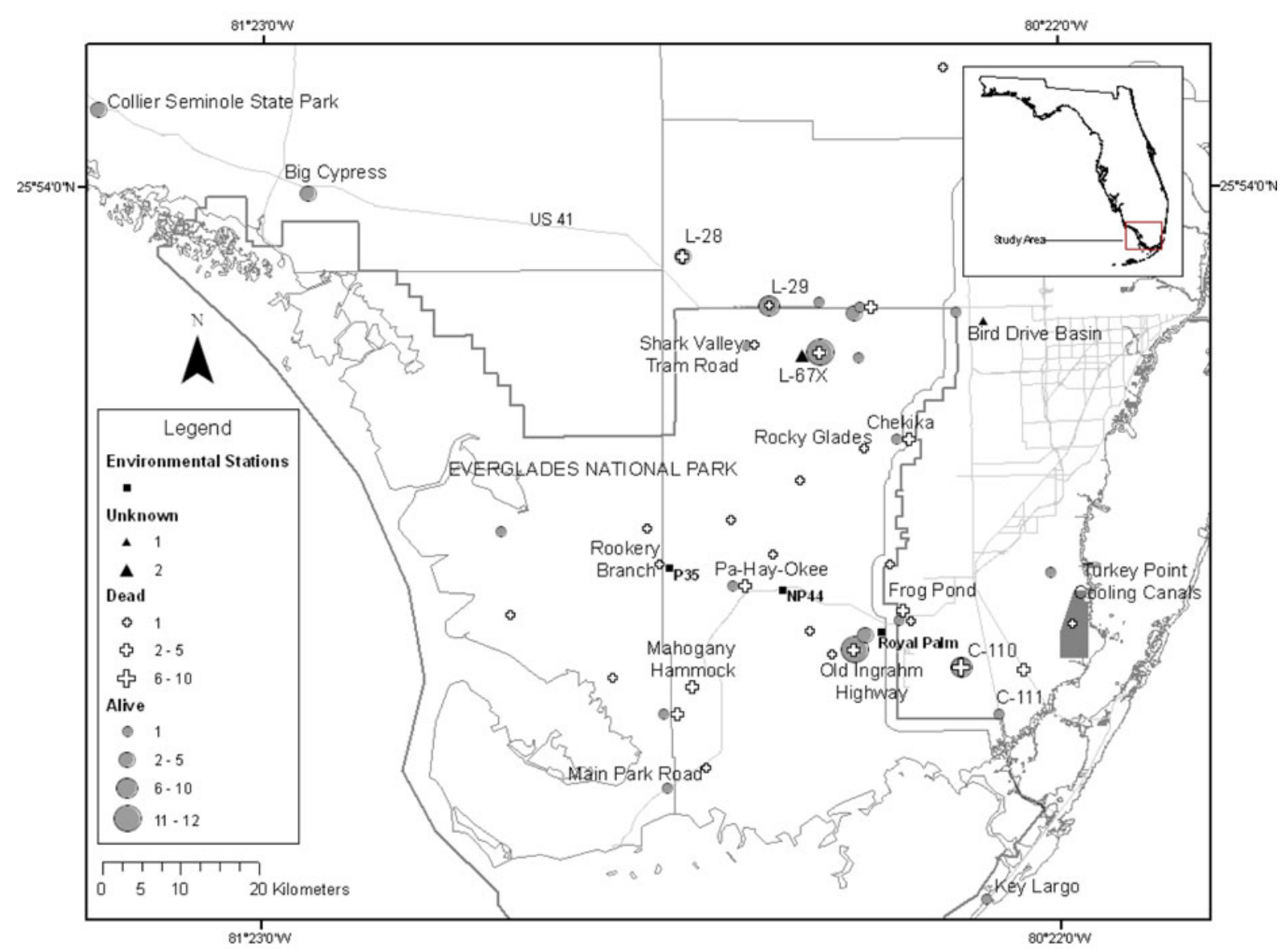

Fig. 1 Locations in south Florida of python search efforts, python captures (live and dead), and environmental data stations 
observations from colleagues and ENP staff. Additional pythons were encountered while radio-tracking snakes on the ground.

To determine correlates with python mortalities, environmental data (air temperature, surface water temperature, and rainfall) were obtained from ENP weather station records. No single weather station in ENP recorded all three environmental variables; hence, we obtained data from the closest station that recorded each variable. We used air temperature recorded at Royal Palm, surface water temperature from station P35, and rainfall from NP44.

\section{Results}

Nine of 10 telemetered pythons (90\%; all 8 females and 1 of 2 males) died during the cold period of 2-11 January 2010. All 10 telemetered pythons were found on the surface of the ground or in vegetation. The lone survivor was found in a hardwood hammock (forest). Six of the nine dead pythons were found on tree islands, one in a marl prairie, one along an ecotone between mangrove forest and sawgrass marsh, and one in a hardwood hammock. Four of the nine dead pythons were partially covered by vegetation and one had small bite marks on its body, presumably from a rodent. Two of the pythons appeared dead when found but then partially revived after being transferred to a laboratory maintained at $23^{\circ} \mathrm{C}$; one of these died within $24 \mathrm{~h}$, and the second never fully recovered and was subsequently euthanized.

One hundred and four non-telemetered pythons were found between 2 January and 4 February 2010.
Among those 99 had a date and fate (alive or dead) associated with them. Fifty-nine $(60 \%)$ were found alive and $40(40 \%)$ were found dead. Among the dead were 13 individuals whose death could not be connected to the cold snap; these snakes were found after being run over by a mower $(n=2)$, while being carried around by an alligator $(n=3)$, dead on roadways $(n=3)$, or killed by humans $(n=5)$ (Fig. 2). One hundred and one non-telemetered pythons were documented as being associated with a specific habitat type. Among these, 84 (83\%) were found in artificial habitats such as levees, canals, and roads; of these, 32 (38\%) were found dead. Seventeen (17\%) non-telemetered pythons were observed in natural habitats, and $9(53 \%)$ of these were dead. Overall, $52(87 \%)$ of 60 surviving non-telemetered pythons were found associated with artificial habitats. Sex was determined for 50 of the 104 non-telemetered snakes (48\%); of the 12 females identified 2 were dead, and of the 38 males identified 4 were dead. Recovered dead snakes averaged $260.4 \mathrm{~cm}$ total length (TL) (53.7 SD) with a range of 167$433 \mathrm{~cm} \mathrm{TL}$, representing juveniles and adults of both sexes.

Air and surface water temperatures in ENP for the record cold spell in January 2010 are presented in Fig. 3. During a 14-day period starting on 2 January 2010, daily minimum air temperatures fell below $10^{\circ} \mathrm{C}$ for 12 days and below $15^{\circ} \mathrm{C}$ for all 14 days. Maximum daily water temperatures remained below $15^{\circ} \mathrm{C}$ for most of the period. Both air and water temperatures fell to their lowest on 11 January (Fig. 3), and ice was observed on the surface of shallow water south of Florida City adjacent to southeastern ENP.
Fig. 2 Summary of Burmese pythons found alive and dead between 2 January and 4 February 2010. Cause of death for pythons summarized here were as a result of the cold snap and other circumstances (snakes found after being run over by a mower, while being carried around by an alligator or found dead on roadways)

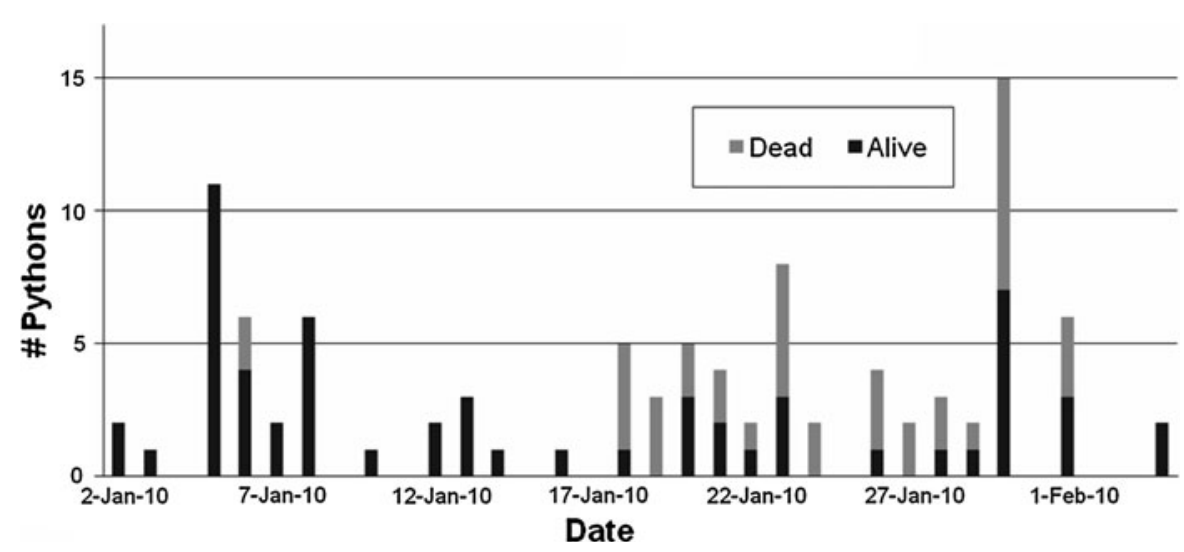



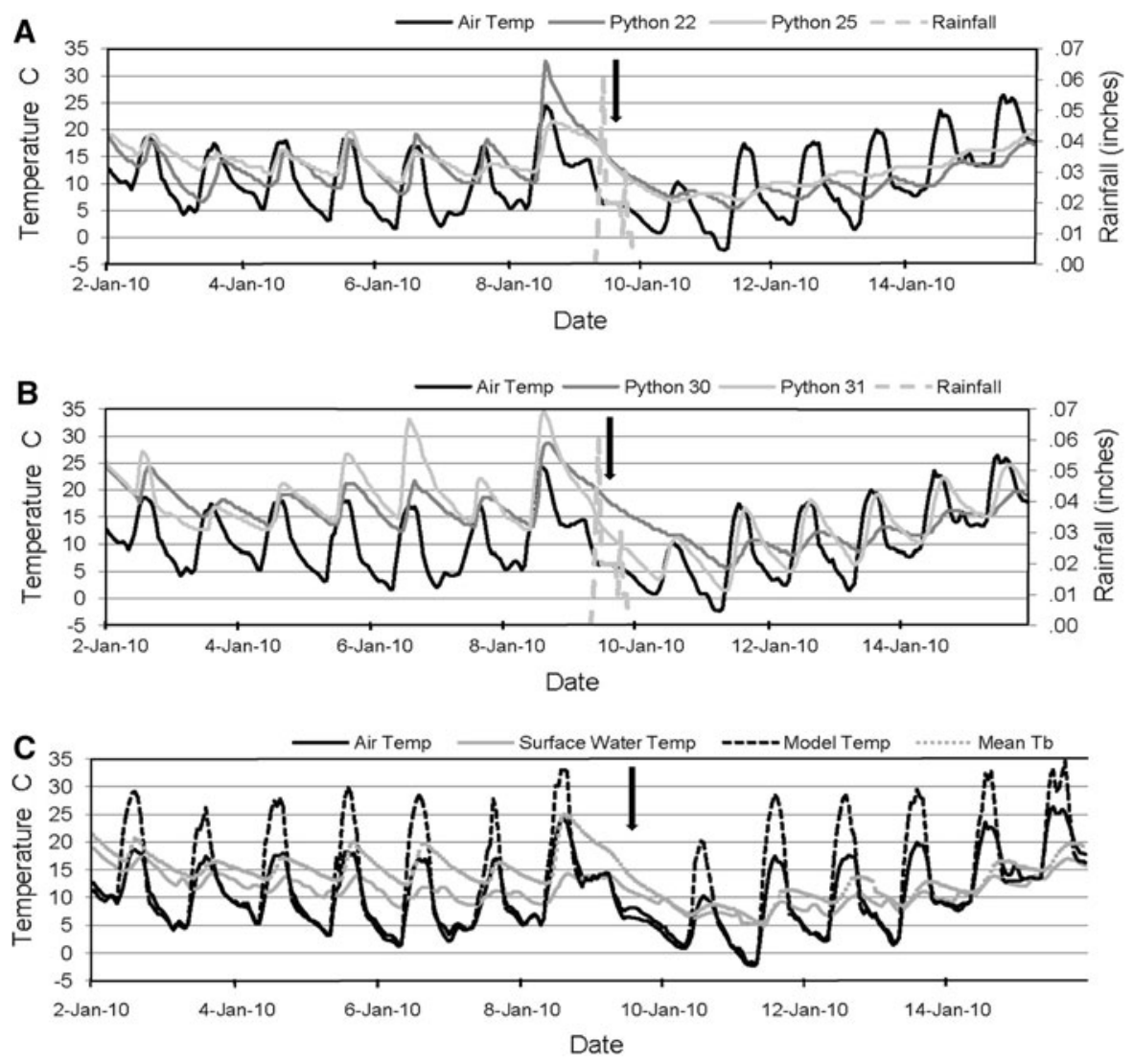

Fig. 3 Summary of air temperature (Royal Palm), along with hourly python body temperature (Tb) (a and $\mathbf{b})$, surface water temperature (P35), rainfall (NP44), and snake model and mean python $\mathrm{Tb}$ from within Everglades National Park from 2 January until 16 January 2010 (c). No one station recorded all variables, so the three closest stations were used for this summary. Note that although air temperature rarely exceeded $20^{\circ} \mathrm{C}$ before 9 Jan, snakes frequently maximized body temperature during the daytime (i.e., snake temperature

We recovered temperature data loggers from eight dead telemetered pythons. Among these individuals, $\mathrm{Tb}$ fluctuated daily with minimum temperatures below $10^{\circ} \mathrm{C}$ and maximum temperatures above $30^{\circ} \mathrm{C}$ prior to 9 January (Fig. 3), similar to data collected from telemetered pythons in similar habitats over previous winters and indicative of active thermoregulation. The maximal daily python temperatures reflect increased $\mathrm{Tb}$ likely from basking behavior (i.e., $\mathrm{Tb}$ matched snake model temperatures). Body temperatures declined substantially during the coldest period (9-11 January) so that maximum snake temperatures were $<10^{\circ} \mathrm{C}$ and in matches snake model temperature). From 9 to 11 Jan, snake temperatures dropped precipitously as environmental temperatures decreased to below $0^{\circ} \mathrm{C}$ on the morning of 11 January. Snake thermal patterns began changing on 10 January (arrows) and after 11 January snake thermal patterns changed so that maximal snake temperatures more closely matched air temperature indicating a lack of behavioral thermoregulation by the snakes. Presumably, most of the snakes died sometime between 10 and 13 January

some snakes $<5^{\circ} \mathrm{C}$ on the morning of 11 January. After 11 January, $\mathrm{Tb}$ of the dead individuals tracked more closely with air temperature, indicating a lack of active thermoregulation (Fig. 3). Comparison of $\mathrm{Tb}$ of dead pythons and model temperatures between 1,000 and $1,700 \mathrm{~h}$ when snakes typically actively thermoregulate for 4 days before and 4 days after the cold snap indicated active thermoregulation before the cold snap $\left(R^{2}=0.277\right)$ and a lack of thermoregulation afterwards $\left(R^{2}=0.025\right)$. Although the exact time snakes died is unknown, a lack of thermoregulatory behavior after 11 January indicates that the snakes were either dead or incapacitated at that time. 


\section{Discussion}

Unusually cold temperatures in January 2010 were associated with mortality of Burmese pythons in the Florida Everglades, and it is possible that the mortality observed among telemetered pythons was typical of pythons in natural habitats within ENP. However, mortality may have been lower in artificial habitats, as discussed below. It is unclear whether python mortality was exacerbated by the duration of the cold event, the extremely cold temperatures at the end of the period, the sequence of events including a long persistent rain prior to plunging temperatures, or some combination of these factors. However, both the lack of active thermoregulation in telemetered pythons during and immediately after 11 January (Fig. 3) and the increase in sightings of dead pythons after 11 January (Fig. 2) suggest that mortality or incapacitation of pythons occurred during this time period. While it is indisputable that large numbers of pythons died, attempts to interpret these deaths with respect to python ecology are complicated by a number of factors, including behavior, availability of refuges, and unknown variation in detection probabilities.

Telemetered pythons appeared to exhibit maladaptive behaviors during the cold spell, as evidenced by observations that all 10 individuals were found on the surface rather than in sheltered refugia. Evidence from other snakes (and crocodilians) suggests that a major difference between tropical and temperate species is their thermoregulatory behavior (Lang 1987; Shine and Madsen 1996). This difference in behavior between temperate and tropical species has been well described for crocodilians. Temperate species such as American alligators (Alligator mississippiensis) are more likely to deliberately seek heat and avoid cold than are tropical species such as American crocodiles (Crocodylus acutus) or spectacled caimans (Caiman crocodilus) (Lang 1987; Brandt and Mazzotti 1990). Lang (1987) described both alligators and crocodiles basking to maintain $\mathrm{Tb}$ on cool days; however, when temperatures cooled further tropical crocodiles continued to bask despite cold air temperatures, whereas warm-temperate alligators avoided basking and instead retreated to warmer refugia in the water. Brandt and Mazzotti (1990) confirmed this observation for alligators and caimans placed in an outdoor enclosure at the Savannah River Ecology Laboratory in Aiken, South
Carolina. In that study, both species basked during cool weather but alligators retreated to the water during freezing temperatures whereas caimans did not; the latter died as a result. Maladaptive behavior of basking during freezing temperatures appeared to be responsible for the deaths of at least some of the Burmese pythons documented here. Avery et al. (2010) observed similar results for Burmese pythons maintained in an outdoor enclosure with thermal refugia provided in Gainesville, Florida during the same time period. Avery et al. (2010) ascribed mortality of 7 out of 9 pythons to cold temperatures. They also suggested that this cold related mortality was related to maladaptive behavior of the captive pythons that neither avoided cold temperatures nor sought available warm temperatures.

If inappropriate behaviors or intolerance to cold contributed to cold-induced python mortality, an obvious question is whether either thermoregulatory behavior during cold weather or physiological tolerance to cold is genetically based. If so, and if there is heritable variation in behavior or physiology within the Florida population of Burmese pythons, then the cold event might have exerted selective pressure on the population in favor of individuals with greater physiological cold tolerances or appropriate thermoregulatory behavior (i.e., refuge-seeking). The native range of Burmese pythons includes regions with winter lows that regularly drop below freezing (Zhao and Adler 1993; Schleich and Kästle 2002), indicating that populations of this species can persist in areas cooler than south Florida. However, most Burmese pythons in the international live animal trade are sourced from Southeast Asia (Groombridge and Luxmoore 1991). If pythons from tropical areas exhibit reduced tolerance to cold as opposed to more temperate populations, and if Florida pythons are sourced only from tropical areas, then the Florida population may have a limited ability to spread northward (Rodda et al. 2009).

In some snakes, thermoregulatory and other behavioral tactics appear to be set early in life, and exposure to novel thermal or habitat conditions later in ontogeny can provoke maladaptive behaviors (Kingsbury and Attum 2009; Aubret and Shine 2009). The python population in south Florida has probably not previously experienced such cold temperatures as those in early 2010; thus the population may be thermally naïve, providing an alternative 
hypothesis for observations of cold-induced mortality. Because no young-of-the-year pythons (live or dead) have been found since the cold event, it remains to be seen whether recent experience with cold weather will affect future behavior of pythons.

All populations of large-bodied pythons and boa constrictors inhabiting areas with cool winters, including northern populations of Burmese pythons in their native range, appear to rely on use of refugia to escape winter temperatures (Bhupathy and Vijayan 1989; Chiaraviglio et al. 2003; Alexander 2007; Waller et al. 2007). These refugia are usually burrows or other subterranean retreats, but deeper water may also be used. All of the 10 radio-telemetered pythons were resident in natural habitats of the Everglades ecosystem, an area characterized by perennially high water tables and seasonal flooding. Although holes in the karst limestone underlying much of this area are abundant, most such holes remain flooded (Loftus et al. 2001). Dry refugia in ENP tend to be limited to uprooted trees and dense clumps of grass, two types of thermal refugia that could easily have their capacity to insulate reduced by precipitation during a cold persistent rainfall. The apparently inappropriate behaviors exhibited by some pythons, including remaining on the surface during inclement weather, may be the result of a lack of suitable thermal refugia in Everglades habitats: the sole surviving telemetered python was found in a large hardwood hammock with thick vegetation and leaf litter, a habitat that may have been drier than the small tree islands and marl prairie used by most pythons that died. In contrast, artificial habitats, especially raised levees associated with canals and roads, have abundant refugia (burrows, erosional holes, etc.) that would be more likely to remain dry and thermally secure. If availability of refugia in areas with high water tables limits ability to escape from cold, then we can anticipate occasional python population reductions in future severe cold snaps in the Everglades and similar habitats. However, we would expect higher survival in drier natural areas with burrows and large tree hollows and in artificial habitats as described above; paradoxically, this could allow relatively higher python survival in areas outside the Everglades which are mostly located farther to the north. Our observations of non-telemetered pythons were especially helpful in illustrating this point: most pythons known to have survived the cold event were found in elevated areas, and all 6 pythons found in higher areas to the northwest of ENP (Collier-Seminole State Park, Big Cypress National Preserve) were alive. Using radiotelemetric data from Everglades National Park alone would likely have provided a skewed view of overall mortality rates. Data from the non-telemetered pythons are also likely to be skewed, as a result of differences in detection probabilities among live and dead snakes; however, these data provide valuable insight on habitat-based variability in mortality rates.

If mortality of telemetered pythons is due to maladaptive behaviors or genetically fixed cold intolerance rather than unavailability of suitable refugia, then range expansion hypotheses for Burmese pythons in the United States may warrant re-evaluation. The inappropriate behavior by Burmese pythons during the cold spell was more like that of a tropical reptile whose geographic range extends into warm temperate or subtropical areas than that of a warm temperate reptile whose geographic range extends into subtropical or tropical areas (e.g., American alligators). Therefore we hypothesize that Burmese pythons are not likely to reach the distributional limits of alligators in the US, with the caveat that Burmese pythons from a different genetic background may respond differently. Consistent with this hypothesis, Rodda et al. (2009) stated that Burmese pythons found in temperate areas of the native range appear to hibernate in the winter. Our results suggest that at least some Burmese pythons in southern Florida did not seek refuge during the cold spell, but that others appeared to use refugia. We could not distinguish between python use of refugia for thermal or other purposes.

Adult female pythons died during the cold event, likely reducing overall recruitment in the population in 2010. Removal of reproductively mature individuals from the population via direct mortality or reduced capacity to reproduce will suppress population growth rates (Caswell 1982; Heppell 1998), and population growth may be further reduced if there is significant juvenile mortality. Future population modeling efforts to predict impacts of extreme cold events should consider the effect of such unanticipated removal of individuals on survival and fecundity. Such modeling efforts should also include stochastic freeze conditions at a rate equivalent to the historic rate of freezes in south Florida (Storey and Gudger 1936; Storey 1937), with the caveat that climate change scenarios should also be incorporated. 
Knowledge of detectability of an invasive species is important for planning control and eradication programs (Christy et al. 2010). Pythons are less detectable in natural areas than in artificial habitats, but are more detectable in both areas after a cold spell. That pythons are apparently more detectable in artificial habitats is likely a result of a combination of accessibility and visibility. Pythons may also have been more visible to human researchers during this study because the snakes appeared to increase the amount of time spent basking after the cold event. Because maximizing removal rates is an important component of invasive species control (Christy et al. 2010), timing rapid responses (Stanford and Rodda 2007) in suitable habitats during and after unusual climatic events might increase removal rates of pythons.

Acknowledgments This research was supported by the US Geological Survey Priority Ecosystems Science program, the US National Park Service Critical Ecosystems Studies Initiative, and the South Florida Water Management District. We thank T. Kiechkefer and T. Hill for tracking and collecting pythons, J. Vinci for making figures, S. Williams for formatting the manuscript, and R. Harvey for editing the manuscript. Everglades National Park agents, park staff, park partners, and visitors assisted by reporting observations and helping to recover pythons. We are especially indebted to B. Hill of the South Florida Water Management District for his reports. This manuscript was greatly improved by comments from $\mathrm{H}$. Waddle, P. Schofield and both anonymous reviewers. Permits and approvals required for this research were obtained from the US National Park Service and the Animal Research Committee at the University of Florida. References to non-USGS products and services are provided for information only and do not constitute endorsement or warranty, expressed or implied, by the US Government, as to their suitability, content, usefulness, functioning, completeness, or accuracy.

Open Access This article is distributed under the terms of the Creative Commons Attribution Noncommercial License which permits any noncommercial use, distribution, and reproduction in any medium, provided the original author(s) and source are credited.

\section{References}

Alexander GJ (2007) Thermal biology of the Southern African Python (Python natalensis): does temperature limit its distribution? In: Henderson RW, Powell R (eds) Biology of the boas and pythons. Eagle Mountain Publishing, Eagle Mountain, Utah, pp 50-75

Aubret F, Shine R (2009) Thermal plasticity in young snakes: how will climate change affect the thermoregulatory tactics of ectotherms? J Exp Biol 213:242-248
Avery M, Engeman R, Keacher K, Humphrey J, Bruce W, Mathies T, Mauldin R (2010) Cold weather and the potential range of invasive Burmese pythons. Biol Invasions. doi: 10.1007/s10530-010-9761-4

Beaumont LJ, Gallagher RV, Thuiller W, Downey PO, Leishman MR, Hughes L (2009) Different climatic envelopes among invasive populations may lead to underestimations of current and future biological invasions. Divers Dist 15:409-420

Bhupathy S, Vijayan VS (1989) Status, distribution and general ecology of the Indian Python (Python molurus molurus Linn.) in Keoladeo National Park, Bharatpur, Rajasthan. J Bombay Nat Hist Soc 86:381-387

Brandt LA, Mazzotti FJ (1990) The behavior of juvenile Alligator mississippiensis and Caiman crocodilus exposed to low temperature. Copeia 1990:867-871

Caswell H (1982) Life history theory and the equilibrium status of populations. Am Nat 120:317-339

Chiaraviglio M, Bertona M, Sironi M, Lucino S (2003) Intrapopulation variation in life history traits of Boa constrictor occidentalis in Argentina. Amphib Reptil 24:65-74

Christy MT, Yackel Adams AA, Rodda GH, Savidge JA, Tyrrell CL (2010) Modelling detection probabilities to evaluate management and control tools for an invasive species. J Appl Ecol 47:106-113

Duncan RP, Cassey P, Blackburn TM (2009) Do climate envelope models transfer? A manipulative test using dung beetle introductions. Proc Roy Soc Lond B Biol Sci 267:1449-1457

Fantz A (2010) Pythons and citrus and iguanas, oh my! Frigid Florida copes. CNN US [Internet]. http://www.cnn.com/2010/ US/weather/01/10/us.cold.weather/index.html. Accessed 12 Feb 2010

Fitzpatrick MC, Weltzin JF, Sanders NJ, Dunn RR (2007) The biogeography of prediction error: why does the introduced range of the fire ant over-predict its native range? Global Ecol Biogeogr 16:24-33

Franke J, Telecky TM (2001) Reptiles as pets: an examination of the trade in live reptiles in the United States. The Humane Society of the United States, Washington, DC

Groombridge B, Luxmoore R (1991) Pythons in South-east Asia. A review of distribution, status, and trade in three selected species. Secretariat of the Convention on International Trade in Endangered Species of Wild Fauna and Flora, Lausanne

Hardy DL Sr, Greene HW (1999) Surgery on rattlesnakes in the field for the implantation of transmitters. Sonoran Herpetol 12:25-27

Hardy DL Sr, Greene HW (2000) Inhalation anaesthesia of rattlesnakes in the field for processing and transmitter implantation. Sonoran Herpetol 13:110-114

Hayes KR, Barry SC (2008) Are there any consistent predictors of invasion success? Biol Invasions 10:483-506

Heppell SS (1998) Application of life-history theory and population model analyses to turtle conservation. Copeia 1998:367-375

Hoover C (1998) The US role in the international live reptile trade: Amazon tree boas to Zululand dwarf chameleons. TRAFFIC North America, Washington, DC

Kingsbury BA, Attum O (2009) Conservation strategies: captive breeding, translocation, and repatriation. In: Mullin S, 
Seigel R (eds) Snakes: ecology and conservation. Cornell University Press, Ithaca, pp 201-220

Kraus FR (2009) Alien reptiles and amphibians; a scientific compendium and analysis. Springer, New York

Lang JW (1987) Crocodilian thermal selection. In: Webb GJW, Manolis SC, Whitehead PJ (eds) Wildlife management: crocodiles and alligators. Surrey Beatty and Sons, Chipping Norton, pp 301-317

Loftus WF, Bruno MC, Cunningham KJ, Perry SA, Trexler JC (2001) The ecological role of karst wetlands of southern Florida in relation to system restoration. In: Proceedings First annual meeting, US Geological Survey. Karst Interest Group, St. Petersburg, Florida, February 13-16, 2001. Water-Resources Investigations Report 01-4011

Meshaka WE, Butterfield BP, Hauge JB (2004) Exotic amphibians and reptiles of Florida. Krieger Publishing Company, Melbourne

NOAA (2010) Historic cold weekend in south Florida. NOAA, National Weather Service, Weather Forecast Office, Miami

Peterson CR, Gibson AR, Dorcas ME (1993) Snake thermal ecology: the causes and consequences of body temperature variation. In: Seigel RA, Collins JT (eds) Snakes: ecology and behavior. McGraw-Hill Publishing Company, New York, pp 241-314

Phillips SJ, Dudik M, Elith J, Graham CH, Lehmann A, Leathwick J, Ferrier S (2009) Sample selection bias and presence-only distribution models: implications for background and pseudo-absence data. Ecol Appl 19: 181-197

Pimentel D, Zuniga R, Morrison D (2005) Update on the environmental and economic costs associated with alieninvasive species in the United States. Ecol Econ 52: 273-288

Pyron RA, Burbrink FT, Guiher TJ (2008) Claims of potential expansion throughout the US by invasive python species are contradicted by ecological niche models. PLoS ONE 3:e2931

Quinlan P (2010) Cold snap kills, injures Florida turtles, manatees, iguanas, fish. Palm Beach Post [Internet]. http:// www.palmbeachpost.com/news/cold-snap-kills-injuresflorida-turtles-manatees-iguanas-177037.html?imw $=$ Y. Accessed 8 Feb 2010

Randin CF, Dirnböck T, Dullinger S, Zimmermann NE, Zappa M, Guisan A (2006) Are niche-based species distribution models transferable in space? J Biogeogr 33:1689-1703

Reed RN, Rodda GH (2009) Giant constrictors: biological and management profiles and an establishment risk assessment for nine large species of pythons, anacondas, and the boa constrictor. US Geol Surv Open File Rep 1202:1-315

Reinert HK, Cundall D (1982) An improved implantation method for radiotracking snakes. Copeia 1982:702-705
Rodda GH, Jarnevich CS, Reed RN (2009) What parts of the US mainland are climatically suitable for invasive alien pythons spreading from Everglades National Park? Biol Invasions 11:241-252

Schleich HH, Kästle W (2002) Amphibians and reptiles of Nepal. ARG Gantner Verlag, Ruggell

Shine R, Madsen T (1996) Is thermoregulation unimportant for most reptiles? An example using water pythons (Liasis fuscus) in tropical Australia. Physiol Zool 69:252-269

Snow RW, Krysko KL, Enge KM, Oberhofer L, WarrenBradley A, Wilkins L (2007a) Introduced populations of Boa constrictor (Boidae) and Python molurus bivittatus (Pythonidae) in southern Florida. In: Henderson RW, Powell R (eds) The biology of boas and pythons. Eagle Mountain Publishing, Eagle Mountain, pp 416-438

Snow RW, Brien ML, Cherkiss MS, Wilkins L, Mazzotti FJ (2007b) Dietary habits of Burmese python, Python molurus bivittatus, from Everglades National Park, Florida. Herpetol Bull 101:5-7

Stanford JW, Rodda GH (2007) The brown treesnake rapid response team. In: Witmer GW, Pitt WC, Fagerstone KA (eds) Managing vertebrate invasive species: proceedings of an international symposium. USDA/APHIS Wildlife Services, National Wildlife Research Center, Fort Collins, pp 175-217

Storey M (1937) The relation between normal range and mortality of fish due to cold at Sanibel Island, Florida. Ecology 19:10-26

Storey M, Gudger EW (1936) Mortality of fishes due to cold at Sanibel Island, Florida, 1886-1936. Ecology 17:640-648

van Wilgen NJ, Roura-Pascual N, Richardson DM (2009) A quantitative climate-match score for risk-assessment screening of reptile and amphibian introductions. Environ Manage 44:590-607

Waller T, Micucci PA, Alvarenga E (2007) Conservation biology of the yellow anaconda (Eunectes notaeus) in northeastern Argentina. In: Henderson RW, Powell R (eds) Biology of the boas and pythons. Eagle Mountain Publishing, Eagle Mountain, pp 340-362

Waters S (2010) Gamefish season closed as a precaution. Sun Sentinel [Internet]. http://articles.sun-sentinel.com/201001-18/sports/fl-fishing-ban-0119-20100118_1_snook-tarponand-bonefish-anglers-and-fishing-guides. Accessed 8 Feb 2010

Whitaker R, Captain A (2004) Snakes of India; the field guide. Draco Books, Chengalpattu

Wilcove DS, Rothstein D, Dubow J, Phillips A, Losos E (1998) Quantifying threats to imperiled species in the United States. Bioscience 48:607-615

Zhao E, Adler K (1993) Herpetology of China. Society for the Study of Amphibians and Reptiles, St. Louis 